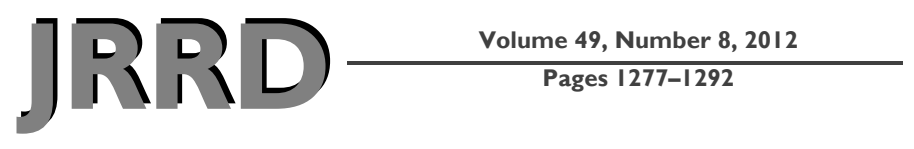

\section{Age-related changes in consonant and sentence processing}

\author{
David L. Woods, PhD $;^{1-2^{*}}$ Zoe Doss; $^{1}$ Timothy J. Herron; $^{1}{ }^{\text {E. William Yund, PhD }}{ }^{1}$ \\ ${ }^{1}$ Human Cognitive Neurophysiology Laboratory, Department of Veterans Affairs Northern California Health Care Sys- \\ tem, Martinez, CA; ${ }^{2}$ Department of Neurology, Center for Neurosciences, and Center for Mind and Brain, University of \\ California Davis, Sacramento, CA
}

\begin{abstract}
Speech understanding in noise declines with age, even in older subjects with normal hearing $(\mathrm{ONH})$. These agerelated declines could reflect reductions in phonological processing ability or impairments in semantic and lexical processing required for sentence understanding. In experiment 1, we used the California Syllable Test (CaST) to examine age-related changes in the ability of subjects to identify consonants in consonant-vowel-consonant syllables in noise. ONH subjects showed impaired performance in comparison with younger subjects with normal hearing, particularly for hard-to-identify consonants, but otherwise showed similar influences of consonant position, lexicality, and vowel nuclei. Regression analyses showed that CaST performance was independently affected by both age and audiometric thresholds. In experiment 2, we examined sentence reception thresholds (SeRTs) using the Quick Speech in Noise Test and Hearing in Noise Test. No significant age-related changes in SeRTs were observed for either test. SeRT preservation in ONH subjects appeared to reflect the ageresistant ability to identify easy consonants in noise as well as intact top-down contextual and lexical processing. These results establish benchmark values that can be used to evaluate the success of audiological rehabilitation in older subjects with hearing impairment.
\end{abstract}

Key words: aging, audiometry, auditory cortex, consonant, hearing loss, learning, nonsense syllables, speech comprehension, threshold, vowel.

\section{INTRODUCTION: EXPERIMENT 1}

Although it is well established that aging impairs speech comprehension in noise in older subjects [1-4], the relative contribution of peripheral and central changes to presbycusic deterioration remains an area of active investigation. Some researchers hypothesize that age-related changes in speech comprehension primarily reflect deterioration in cochlear function [5], whereas others ascribe an important role to deficits in central auditory processing [6-7]. Central deficits may reflect impaired phonological processing [8] or higher-level lexical and semantic impairments that are most clearly revealed in sentence testing [9].

A primary goal of audiological rehabilitation of older subjects with hearing impairment (OHI) is to restore speech understanding to normal levels with hearing aids

\footnotetext{
Abbreviations: $\mathrm{ANOVA}=$ analysis of variance, $\mathrm{B}=$ baseline, $\mathrm{CaST}=$ California Syllable Test, $\mathrm{CVC}=$ consonant-vowelconsonant, HINT $=$ Hearing in Noise Test, HPTA = highfrequency pure-tone average, LPTA $=$ low-frequency pure-tone average, $\mathrm{MRI}=$ magnetic resonance imaging, $\mathrm{NS}=$ not significant, $\mathrm{OHI}=$ older (subjects with) hearing impairment, $\mathrm{ONH}=$ older (subjects with) normal hearing, $\mathrm{P} / \mathrm{I}=$ performance/intensity, QuickSIN $=$ Quick Speech in Noise Test, $\mathrm{SD}=$ standard deviation, $\mathrm{SeRT}=$ sentence reception threshold, $\mathrm{SNHL}=$ sensorineural hearing loss, SNR = signal-to-noise ratio, $\mathrm{SPL}=$ sound pressure level, $\mathrm{YNH}=$ younger (subjects with) normal hearing.

"Address all correspondence to David L. Woods, PhD; Neurology Service (127E), Department of Veterans Affairs Northern California Health Care System, 150 Muir Rd, Martinez, CA 95553; 925-372-2571; fax: 925-228-5738.

Email: dlwoods@ucdavis.edu

http://dx.doi.org/10.1682/JRRD.2011.08.0150
} 
[10] and/or with perceptual training [11]. The appropriate target for OHI subjects is to restore their speech comprehension to age-normal performance levels observed in older subjects with normal hearing $(\mathrm{ONH})$. Hence, the careful measurement of speech comprehension in noise in ONH subjects is necessary to provide a reliable benchmark against which the success of audiological rehabilitation can be measured.

A number of studies have suggested that phonological processing in noise is impaired by advancing age [12-14]. For example, Gelfand et al. used the City University of New York Nonsense Syllable Test to examine consonant discrimination in younger and older subjects with audiometric thresholds better than $25 \mathrm{~dB}$ at 250 to $8,000 \mathrm{~Hz}$ [15]. They found significant differences in performance between the younger (20-49 yr) and older (60-69 yr) subject groups despite similar patterns of consonant confusions. The differences persisted after factoring out individual pure-tone thresholds in the 250 to $4,000 \mathrm{~Hz}$ range but were correlated with thresholds at $8,000 \mathrm{~Hz}$, suggesting that subtle changes in hearing acuity contributed to consonant identification deficits, even in older adults with virtually normal thresholds.

In experiment 1, we used the California Syllable Test (CaST) [16-17] to compare consonant identification in younger subjects with normal hearing (YNH) and $\mathrm{ONH}$ subjects. The CaST measures the signal-to-noise ratio (SNR) required to identify consonants in consonantvowel-consonant (CVC) syllables presented in speech spectrum noise. It uses the signal detection measure $d^{\prime}$ to quantify the SNRs necessary to identify each of 20 leading and 20 trailing consonants. In previous studies, we demonstrated that consonants differ substantially in the SNRs required for their identification [16]. Group A consonants $(/ \mathrm{J} /, / \mathrm{t} /, / \mathrm{t} /, / \mathrm{s} /, / \mathrm{z} /, / \mathrm{d} / \mathrm{z} /$, and $/ \mathrm{r} /)$ in isolated syllables are accurately identified at SNRs near $0 \mathrm{~dB}$, i.e., similar to the SNRs obtained in sentence reception threshold (SeRT) testing of YNH subjects. Group B consonants $(/ \mathrm{d} /, / \mathrm{g} /, / 1 /, / \mathrm{m} /, / \mathrm{n} /, / \mathrm{f} /$, and $/ \mathrm{k} /)$ are accurately identified at SNRs that are 4 to $10 \mathrm{~dB}$ above SeRTs, suggesting that the identification of these consonants may make some contribution to sentence comprehension at SNRs that characterize SeRTs. Finally, group C consonants $(/ \mathrm{b} /, / \mathrm{v} /, / \mathrm{d} /, / \eta /, / \theta /, / \mathrm{p} /$, and $/ \mathrm{h} /)$ are identified at SNRs that are 10 to $40 \mathrm{~dB}$ above SeRT SNRs and therefore likely make minimal contributions to sentence comprehension using existing SeRT instruments.
Previous studies have found age-related decrements in consonant identification when consonants are presented in nonsense syllables $[8,12,15,18]$. However, Dubno et al. found no overall age-related changes in word recognition in audiometrically matched subjects ranging in age from 55 to $84 \mathrm{yr}$, suggesting that agerelated deficits in consonant identification may not be evident for lexically meaningful tokens [19]. Because the CaST contains both words and nonsense syllables, it permits a comparison of the effects of lexicality on consonant identification in $\mathrm{ONH}$ and $\mathrm{YNH}$ subjects.

In experiment 2, we evaluated higher-level semantic processing using two SeRT measures: the Quick Speech in Noise Test (QuickSIN) [20] and Hearing in Noise Test (HINT) [21]. Greater age-related decrement in SeRTs than in CaST thresholds would suggest age-related impairments in higher-level semantic processing. In contrast, greater decrements in CaST thresholds than in SeRTs would suggest that ONH subjects were able to compensate for age-related declines in consonant processing through enhanced reliance on alternative vowel and semantic cues.

\section{METHODS}

\section{Subjects}

Sixteen ONH subjects (14 female, age 60-79 yr, thresholds $\leq 25 \mathrm{~dB}$ hearing level at 250-4,000 Hz) and 16 YNH subjects (21-33 yr) participated. Each subject underwent three testing sessions over 3 to $11 \mathrm{~d}$. The results from the YNH subjects have been reported in detail elsewhere [16-17].

Figure 1 shows the audiograms for the subject groups. All subjects had symmetric thresholds in the two ears (i.e., within $10 \mathrm{~dB}$ ). We obtained low-frequency pure-tone average (LPTA) thresholds by averaging thresholds at 250,500, 1,000, 1,500, and 2,000 Hz. We obtained high-frequency pure-tone average (HPTA) thresholds by averaging thresholds at 3,000, 4,000, 6,000 , and $8,000 \mathrm{~Hz}$. Not surprisingly, although still within the range of normal hearing up to $4,000 \mathrm{~Hz}$, the ONH subjects had somewhat poorer audiometric thresholds than the YNH subjects, particularly at higher frequencies (Figure 1). For example, relative to the mean of YNH subjects, ONH subject threshold elevations averaged $3.6 \mathrm{~dB}$ for the LPTA (standard deviation [SD]: $3.6 \mathrm{~dB}$; range: -1.75 to $9.25 \mathrm{~dB}$ ) and $15.6 \mathrm{~dB}$ for the 


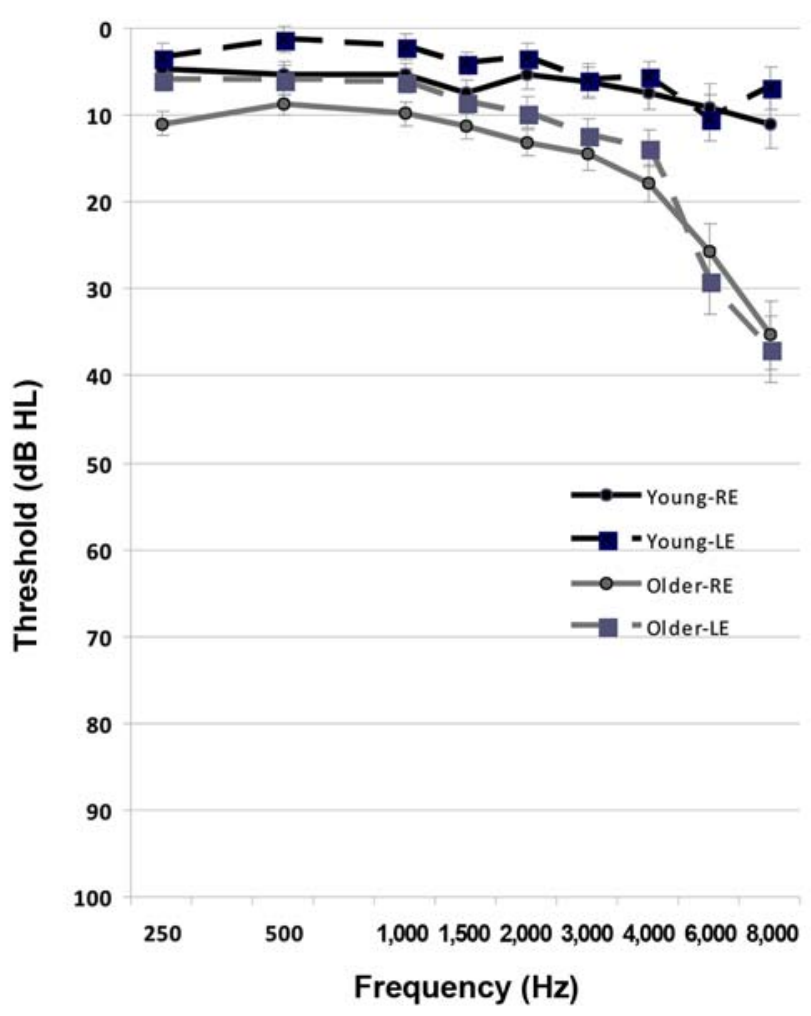

Figure 1.

Audiograms: average left ear (LE) and right ear (RE) audiograms for younger and older subjects with normal hearing. Error bars show standard error of mean. $\mathrm{HL}=$ hearing level.

HPTA (SD: $9.3 \mathrm{~dB}$; range: -1.6 to $34.6 \mathrm{~dB}$ ). There were significant correlations between age and LPTA $(r=0.53$, $p<0.002)$ and age and HPTA $(r=0.69, p<0.001)$. There was also a strong correlation between LPTA and HPTA $(r=0.68, p<0.001)$.

\section{Syllable Tokens}

The CaST [16-17] includes 1,200 CVC syllables containing 20 leading consonants, 20 coda consonants, and 3 vowels $(/ \alpha /, / \mathrm{I} /, / \mathrm{u} /)$ that are exhaustively combined to create 1,200 different tokens $(20 \times 3 \times 20)$. Nineteen of the consonants $(/ \mathrm{p} /, / \mathrm{t} /, / \mathrm{k} /, / \mathrm{f} /, / \theta /, / \mathrm{s} /, / \mathrm{f} /, / \mathrm{g} /, / \mathrm{b} /, / \mathrm{d} /$, $/ \mathrm{g} /, / \mathrm{v} /, / \mathrm{d} /, / \mathrm{z} /, / \mathrm{d} /, / \mathrm{m} /, / \mathrm{n} /, / 1 /$, and $/ \mathrm{r} /$ ) occur in leading and coda syllable positions, $/ \mathrm{h} /$ occurs only as a leading consonant, and $/ \eta /$ only as a coda. Two recordings of each syllable were obtained from four phonetically trained talkers, creating a corpus of 9,600 CVCs. For each token, the central $100 \mathrm{~ms}$ vowel segment was identified by manual inspection.

\section{Noise Adjustment}

We used dynamically adjusted, speech-spectrum noise to mask leading and coda consonants. We obtained individual noise spectra from each talker, and 100 different 1,200 ms noise segments were generated and randomly sampled during test sessions to mask spoken CVCs.

\section{Procedures}

We performed testing in a single-walled, soundattenuating room. The interior walls were covered by $2.5-\mathrm{cm}$ acoustic foam, reducing ambient third-octave noise levels to less than $20 \mathrm{~dB}$ sound pressure level (SPL) from 250 to $4,000 \mathrm{~Hz}$. We presented soundfield stimuli through loudspeakers (AV 40, M-Audio; Irwindale, California) spaced $1.16 \mathrm{~m}$ in front of the subject at $\pm 42^{\circ}$ angles. Prior to testing, we trained subjects in identifying unmasked CVCs.

We presented CVCs from each talker in blocks of 30 trials. We controlled stimulus delivery, dynamic masking-noise-level adjustment, response recording, and $d^{\prime}$ calculations using Presentation ${ }^{\circledR}$ software (Neurobehavioral Systems, Inc; Albany, California). We presented a tone cue (100 ms $1.0 \mathrm{kHz}$ tone, $70 \mathrm{~dB} \mathrm{SPL})$ prior to the onset of each trial (Figure 2). Two independent selected talker-specific noise bursts (1,200 ms duration) were then presented from the two loudspeakers. The CVC was then presented through both loudspeakers after a random noise-to-CVC delay. An investigator transcribed responses and queried the subject via intercom when responses could not be scored. Response transcription occurred during the intertrial interval (approximately $2.5 \mathrm{~s}$ ) so that each 720syllable test required 48 to $60 \mathrm{~min}$.

Syllable intensity randomly varied from 70 to $75 \mathrm{~dB}$ SPL in $1 \mathrm{~dB}$ steps. We measured identification accuracy for each consonant at three consonant-specific SNRs: B (baseline), B -6 , and B $+6 \mathrm{~dB}$ using B SNRs obtained in previous experiments [17]. We randomized SNRs from trial to trial.

During each test session, $720 \mathrm{CVC}$ tokens were pseudorandomly selected from the syllable corpus of 9,600 tokens such that each leading consonant and coda was presented 36 times. Selection was constrained so that each consonant was presented equally at each SNR, with each of the three vowels $(/ \alpha /, / \mathrm{I} /, / \mathrm{u} /)$ and with equal representation of tokens from each of the four talkers. Because vowel errors were rare, we scored only consonant identification. 


\section{Performance Measures}

We used signal-detection measures to quantify consonant identification performance. B SNRs for each leading and coda consonant had been previously adjusted so as to equate the identifiability of different consonants, producing a mean $d^{\prime}$ of approximately $2.20(\sim 65 \%$ correct) in the control YNH subjects [17]. Additional small adjustments had been incorporated to equate the identifiability of tokens spoken by different talkers and containing different vowels. We increased B SNRs by $3.0 \mathrm{~dB}$ when presented to the ONH subjects. Table 1 shows SNRs for specific consonants. They averaged $9.6 \mathrm{~dB}$ for leading consonants and $12.9 \mathrm{~dB}$ for coda.

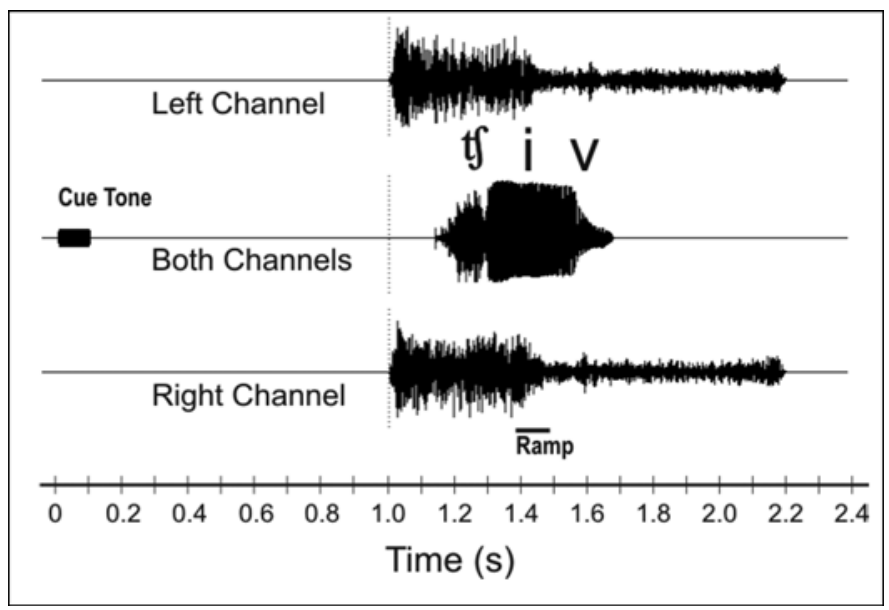

Figure 2.

Trial structure. Trials were cued by $1.0 \mathrm{kHz}$ tone. After $1.0 \mathrm{~s}$, two independent 1,200 ms noise bursts were presented through left and right loudspeakers. Consonant-vowel-consonants (CVCs) were presented simultaneously through both loudspeakers at random intervals after noise burst onset. Noise amplitudes were linearly adjusted over 100 ms interval during midvowel segment of CVC to provide appropriate masking levels for different leading and coda consonants.

\section{Statistical Analysis}

We analyzed the data with multifactorial repeated measures analysis of variance (ANOVA) using CLEAVE (Human Cognitive Neurophysiology Laboratory, East Bay Institute for Research and Education; Martinez, California). We used corrections for heteroscedasticity when appropriate [22]. Because of the large number of comparisons, we initially evaluated age-related changes at a strict criterion $(p<0.01)$. We supplemented ANOVAs with partial Pearson correlation analyses [23] in order to identify relationships between aging, audiometric thresholds, and consonant identification performance.

\section{RESULTS}

Figure 3 shows the age-related differences in SNR thresholds for different consonants. Overall $d^{\prime}$ levels in the ONH group averaged 2.19, an insignificant difference with YNH subjects $\left(d^{\prime}=2.30, F(1,30)=2.77, p<0.11\right)$. We analyzed group differences in dB SNR for the 19 consonants that appeared in both leading and coda position using age (young vs old), position (leading or coda consonant), and consonants as factors. There was a significant main effect of age $(F(1,30)=24.63, p<0.001)$ because mean SNR thresholds were increased by an average of $3.1 \mathrm{~dB}$ in the $\mathrm{ONH}$ subjects. There was also a highly significant main effect of position $(F(1,30)=$ 353.34, $p<0.001$ ) because SNRs were $3.2 \mathrm{~dB}$ lower for leading than for coda consonants. However, we found no significant age $\times$ position interaction. There was also the expected main effect of consonant $(F(1,30)=616.90, p<$ $0.001)$ because mean consonant thresholds varied by more than $42 \mathrm{~dB}$.

As shown in Figure 3, there was also a significant age $\times$ consonant interaction $(F(18,540)=16.98, p<0.001)$ that reflected different age-related threshold elevations for different consonants. Further comparisons showed that significant age-related threshold elevations occurred for all but three consonants $(/ \mathrm{f} /, / \mathrm{J} /$, and $/ \mathrm{r} /)$. We observed age-related elevations in consonant thresholds that exceeded $6.0 \mathrm{~dB}$ for four consonants $(/ \mathrm{f} /, / \theta / / / \mathrm{d} /$, and $/ \eta /)$.

Table 1.

Signal-to-noise levels used for presentation of leading and coda consonants in experiment 1.

\begin{tabular}{|c|c|c|c|c|c|c|c|c|c|c|c|c|c|c|c|c|c|c|c|c|c|}
\hline Consonant & $\mathbf{b}$ & d & g & $\mathbf{r}$ & I & $\eta$ & $\mathbf{n}$ & $\mathbf{m}$ & $\mathbf{v}$ & ठ & $\mathbf{z}$ & ds & tf & $\int$ & $\mathbf{s}$ & $\theta$ & f & $\mathbf{p}$ & $\mathbf{t}$ & $\mathbf{k}$ & h \\
\hline Leading & 13.3 & 6.8 & 9.9 & 5.5 & 13.5 & - & 8.7 & 10.8 & 13.6 & 22.6 & 0.4 & 2.6 & 3.9 & 4.1 & -4.4 & 22.7 & 12.1 & 15.7 & 1.5 & 9.9 & 18.5 \\
\hline Coda & 16.0 & 14.6 & 16.8 & 2.7 & 7.4 & 22.3 & 20.5 & 20.5 & 24.4 & 35.6 & 1.2 & 7.5 & 3.4 & 3.3 & -4.9 & 20.6 & 14.1 & 15.3 & 6.2 & 10.5 & - \\
\hline
\end{tabular}




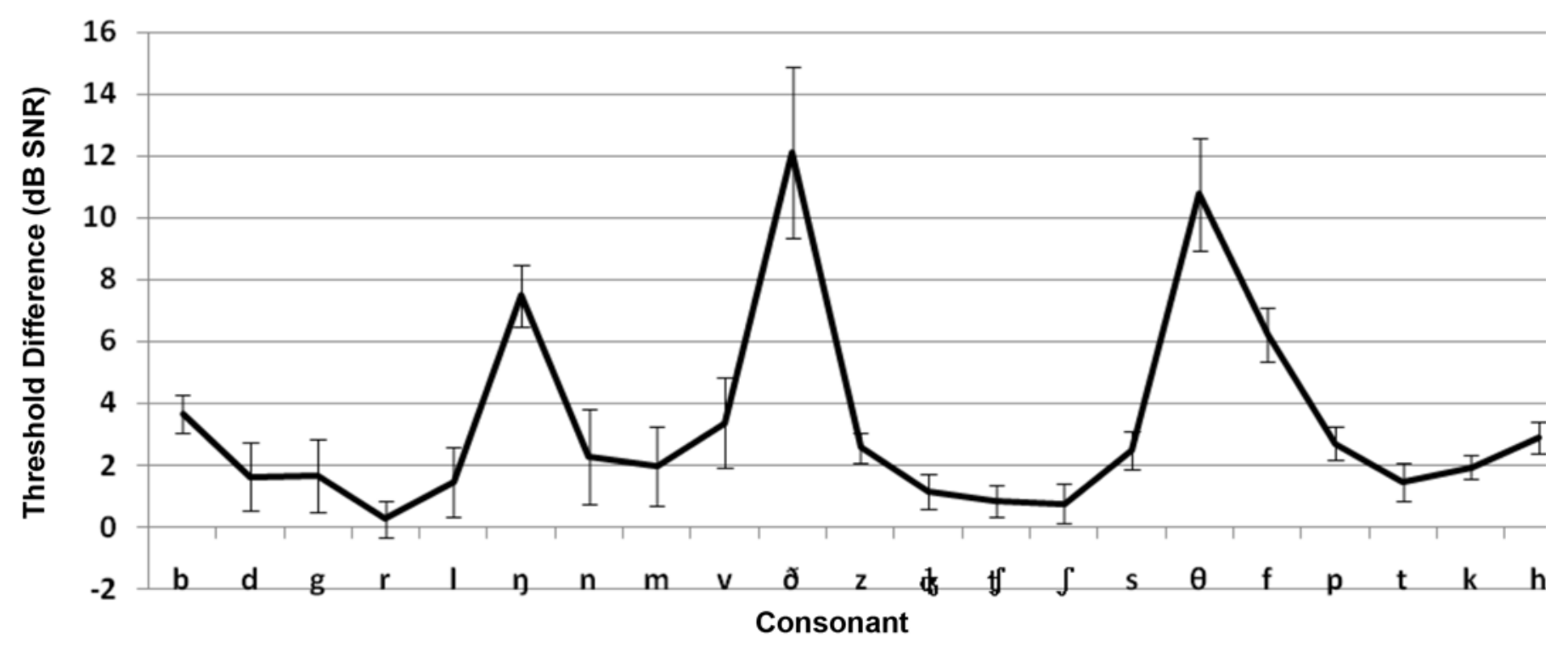

Figure 3.

Age-related changes in consonant identification performance. Threshold differences in dB signal-to-noise ratio (SNR) between older and younger subjects with normal hearing necessary to obtain mean $d^{\prime}$ scores of 2.20. Values have been averaged over leading and coda consonants except for $/ \mathrm{h} /$ and $/ \eta /$. Error bars show standard errors of mean.

Figure 4 shows the SNRs needed to produce $d^{\prime}$ values of 2.20 for the different consonant groups. Aging produced different effects on consonant groups resulting in a significant age $\times$ consonant group interaction $(F(2,60)=30.94$, $p<0.001)$ : thresholds increased with age by $1.36 \mathrm{~dB}$ for group A consonants (mean SNR averaged over groups $=-0.14 \mathrm{~dB}$ ), by $2.54 \mathrm{~dB}$ for group $\mathrm{B}$ consonants (mean SNR $=10.46 \mathrm{~dB}$ ), and by $6.14 \mathrm{~dB}$ for group $\mathrm{C}$ consonants (mean SNR $=20.15 \mathrm{~dB}$ ). Thus, consonant identification thresholds were disproportionately increased for group C consonants, i.e., those consonants that required the highest SNRs for their identification.

We used correlation analysis to further explore relationships between age (in years), audiometric thresholds, and CaST performance. Audiometric thresholds correlated significantly with CaST performance. The LPTA was significantly correlated with thresholds for each consonant group (group A: $r=-0.50, p<0.003$; group $\mathrm{B}: r=-0.59$, $p<0.001$; group C: $r=-0.61, p<0.001)$. We found even larger correlations between HPTA and consonant group thresholds (group A: $r=-0.64, p<0.001$; group B: $r=$ $-0.70, p<0.001$; group C: $r=-0.71, p<0.001$ ). Age also showed significant negative correlations with consonant thresholds for group A $(r=-0.64, p<0.001)$, group B ( $r=$

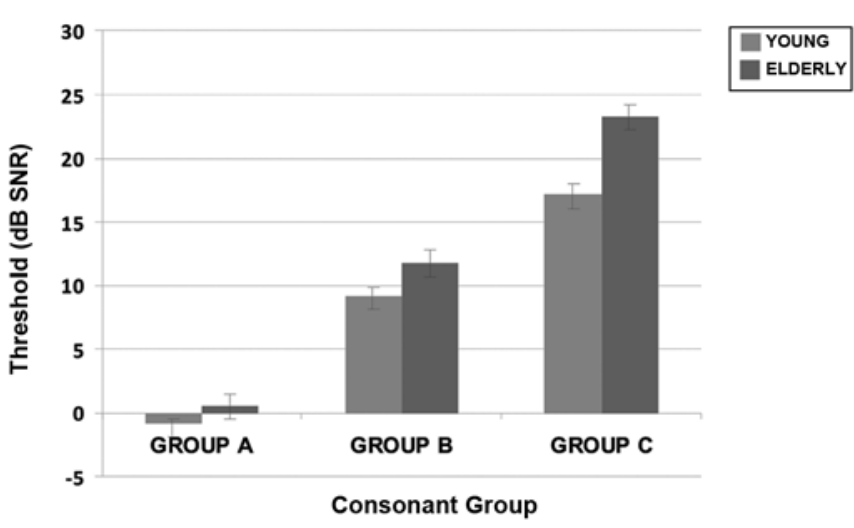

Figure 4.

Consonant group thresholds: average thresholds in $\mathrm{dB}$ signal-tonoise ratio (SNR) for group $A(|\mathrm{~J} /,| \mathrm{t} / /,|\mathrm{t} /,| \mathrm{s} /, \mid \mathrm{z} /, / \mathrm{d} /$, and $/ \mathrm{r} /)$, group B (/d/, /g/, ///, /m/, /n/, /f/, and /k/), and group C (/b/, /v/, /ð/, $/ \eta /, / \theta /, / \mathrm{p} /$, and $/ \mathrm{h} /$ ) consonants for younger and older subject groups with normal hearing. Error bars are standard errors of mean.

$-0.71, p<0.001)$, and group $\mathrm{C}(r=-0.64, p<0.001)$ consonants. Importantly, when the contributions of the audiogram (LPTA and HPTA) were partialled out, significant negative correlations persisted between age and consonant 
thresholds for group A $(r=-0.35, p<0.05)$ and group B $(r=-0.41, p<0.01)$ consonants, but failed to reach significance for group $\mathrm{C}$ consonants $(r=-0.27, p<0.07)$.

\section{Consonant Confusions}

Tables 2 and 3 present the confusion matrices for leading and coda consonants from the ONH subjects at SNRs that were $3 \mathrm{~dB}$ above those used for $\mathrm{YNH}$ subject testing. These SNRs were used in $\mathrm{ONH}$ subject testing and effectively equated overall $d^{\prime}$ performance in the two groups. Confusion matrices for $\mathrm{YNH}$ subjects can be found in Woods et al. [17]. Consistent with Gelfand et al.'s [15] observations, we found that consonant confusions were generally similar in the $\mathrm{ONH}$ and $\mathrm{YNH}$ groups. Figure 5 displays leading and coda consonant confusions

Table 2.

Confusion matrices from older subjects with normal hearing for leading consonants averaged across subjects, signal-to-noise ratios, and voices. Each consonant was delivered on 1,728 trials. Rows are stimuli and columns are responses.

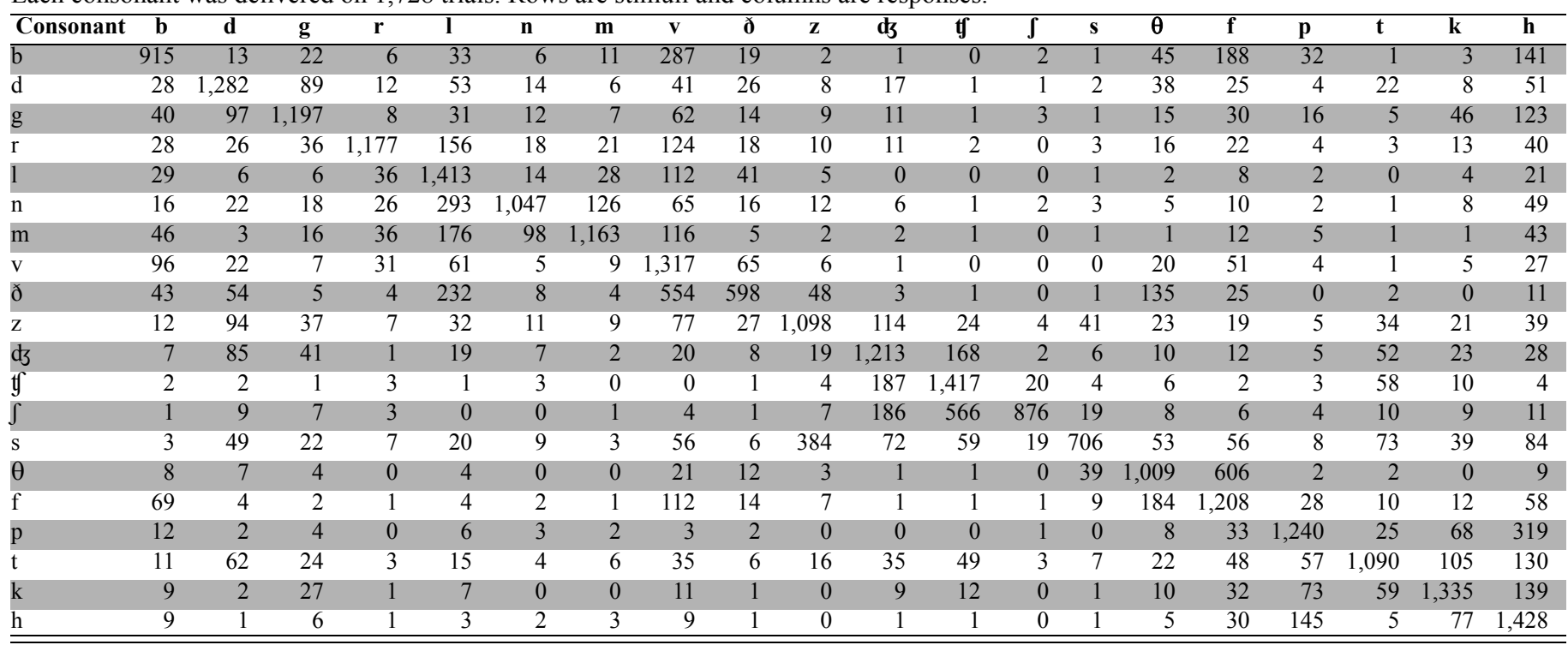

Table 3.

Confusion matrices from older subjects with normal hearing for coda consonants averaged across subjects, signal-to-noise ratios, and voices. Each consonant was delivered on 1,728 trials. Rows are stimuli and columns are responses.

\begin{tabular}{|c|c|c|c|c|c|c|c|c|c|c|c|c|c|c|c|c|c|c|c|c|}
\hline Consonant & b & d & g & $\mathbf{r}$ & I & $\eta$ & $\mathbf{n}$ & $\mathbf{m}$ & $\mathbf{v}$ & ठ & $\mathbf{z}$ & db & tf & $\int$ & $\mathbf{S}$ & $\theta$ & f & $\mathbf{p}$ & $\mathbf{t}$ & $\mathbf{k}$ \\
\hline g & 99 & 70 & 1,113 & 0 & 1 & 9 & 6 & 20 & 269 & 17 & 4 & 5 & 0 & 0 & 2 & 12 & 29 & 18 & 7 & 47 \\
\hline 1 & 25 & 21 & 36 & 53 & 1,076 & 69 & 33 & 66 & 257 & 11 & 12 & 17 & 2 & 5 & 1 & 4 & 14 & 8 & 5 & 13 \\
\hline$\eta$ & 10 & 4 & 7 & 1 & 13 & 949 & 241 & 385 & 107 & 7 & 0 & 1 & 0 & 1 & 1 & 0 & 1 & 0 & 0 & 0 \\
\hline $\mathrm{n}$ & 9 & 6 & 4 & 0 & 5 & 145 & 1,219 & 227 & 99 & 4 & 1 & 3 & 0 & 0 & 4 & 1 & 0 & 0 & 0 & 1 \\
\hline $\mathrm{m}$ & 17 & 3 & 2 & 0 & 6 & 81 & 102 & 1,430 & 78 & 3 & 0 & 0 & 0 & 1 & 1 & 0 & 1 & 2 & 1 & 0 \\
\hline $\mathrm{z}$ & 17 & 53 & 23 & 6 & 5 & 14 & 8 & 26 & 111 & 52 & 924 & 226 & 55 & 39 & 68 & 21 & 10 & 12 & 32 & 26 \\
\hline ds & 9 & 48 & 28 & 3 & 5 & 10 & 8 & 5 & 40 & 6 & 10 & 1,431 & 68 & 19 & 3 & 8 & 6 & 4 & 9 & 8 \\
\hline t5 & 1 & 1 & 2 & 1 & 0 & 3 & 5 & 5 & 4 & 3 & 2 & 169 & 1,347 & 106 & 5 & 8 & 6 & 5 & 35 & 20 \\
\hline $\int$ & 0 & 11 & 6 & 1 & 1 & 7 & 4 & 11 & 11 & 4 & 11 & 132 & 233 & 1,220 & 16 & 14 & 7 & 3 & 17 & 19 \\
\hline $\mathrm{s}$ & 5 & 20 & 22 & 2 & 1 & 12 & 13 & 30 & 42 & 6 & 80 & 110 & 172 & 178 & 821 & 46 & 40 & 16 & 62 & 50 \\
\hline$\theta$ & 5 & 3 & 11 & 3 & 0 & 1 & 0 & 1 & 50 & 13 & 5 & 0 & 1 & 3 & 34 & 1,013 & 546 & 14 & 12 & 13 \\
\hline
\end{tabular}



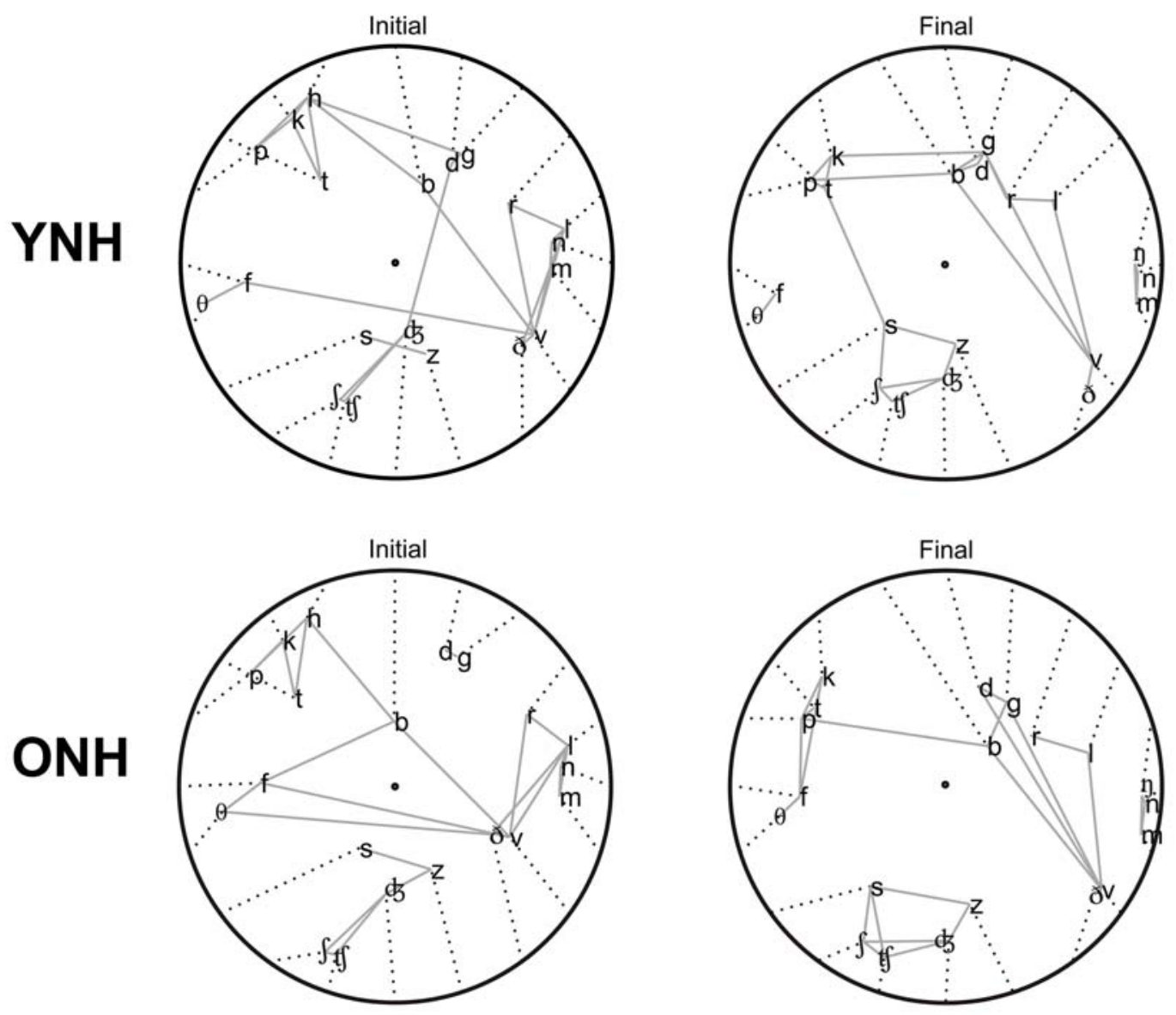

Figure 5.

Consonant confusions: barycentric cluster analysis of consonant confusion patterns of leading (left) and coda (right) consonants for younger subjects with normal hearing $(\mathrm{YNH})$ and older subjects with normal hearing $(\mathrm{ONH})$. See text for further details.

in both subject groups using barycentric clustering [17]. Consonants were initially placed in equidistant positions around a unit circle based on voicing, manner, and place features using the optimized a priori consonant ordering shown in Tables 2 and 3. Unvoiced and voiced consonants were initially positioned on left and right sides of the circle, connected at the bottom across the voiced and unvoiced affricates, and connected at the top across voiced and unvoiced plosives. Then the location of each consonant was modified as an average of its initial position and weighted by its hit rate and the position of every other consonant weighted by the frequency of false responses to that consonant. We used two movement iterations to generate the cluster plots shown. As a result of these iterations, each consonant was displaced from its initial position toward the locations of consonants with which it was confused (dotted lines in Figure 5). Consonant pairs producing the most frequent confusions (top $12.5 \%$, corresponding to total bidirectional confusion rates in excess of approximately $6 \%$ of hits) are connected by solid gray lines.

The age-related differences seen in these barycentric plots primarily reflect the poorer processing of difficult consonants by the $\mathrm{ONH}$ subjects. ONH subjects had more difficulty discriminating /f/ and $/ \theta /$ from plosives (particularly $/ \mathrm{b} /$ for leading consonants and $/ \mathrm{p} /$ and $/ \mathrm{t} /$ for coda consonants). This resulted in the displacement of the $/ f /-/ \theta /$ pair away from the circumference as well as an increased incidence of confusions between this consonant pair and plosives. ONH subjects also more commonly confused the / $/ /-/ \mathrm{v} /$ pair with each other (indicated by their closer apposition on the plots, particularly for 
coda consonants) and made more confusions between this consonant pair and other consonants (i.e., moving them farther away from circumference, particularly for leading consonants). In contrast, affricates and sibilants were less frequently confused with other consonants by the $\mathrm{ONH}$ subjects (particularly in coda position) and so remained closer to the circle circumference.

\section{Vowel Effects}

The influences of vowels on the identification of individual consonants in ONH subjects are shown in Figure 6 and are similar to vowel effects on consonant identification in YNH subjects shown in Woods et al. [17]. ANOVA performed on $d^{\prime}$ scores with age, vowel, position, and consonant as factors showed no significant main effect of vowel $(F(2,60)=2.00$, not significant $[\mathrm{NS}])$ or position $(F(1,30)=0.01$, NS $)$. However, there was a significant vowel $\times$ position interaction $(F(2,60)=102.89, p<0.001)$ because leading consonants were more accurately identified in CVCs containing / $\alpha /$, and coda consonants were identified more accurately in CVCs containing /I/ and, to a lesser extent, /u/. There was also a highly significant consonant $\times$ vowel interaction $(F(36,1080)=80.30, p<$ $0.001)$ that reflected the fact that some consonants were better identified with certain vowels than with others (e. g., nasals were better identified with $/ \alpha /$ than $/ i /$ ). Finally, Figure 6 shows a consonant $\times$ vowel $\times$ position interaction $(F(36,1080)=21.93, p<0.001)$ that reflected differences in consonant/vowel preferences for leading and coda consonants. Interestingly, the effects of vowels on consonant processing were similar in $\mathrm{ONH}$ and $\mathrm{YNH}$ subjects: age $\times$ vowel $(F(2,60)=1.53, \mathrm{NS})$, age $\times$ vowel $\times$ position $(F(2,60)=3.42, p<0.08)$, and age $\times$ vowel $\times$ consonant interactions $(F(36,1080)=1.63$, NS $)$ all failed to reach significance.

\section{Learning Effects}

One possible explanation for the improved performance of YNH subjects is that they learn more effectively than $\mathrm{ONH}$ subjects over successive testing sessions. Figure 7 shows the performance of the $\mathrm{ONH}$ subjects across the three test sessions. A comparison of learning effects in $\mathrm{ONH}$ and $\mathrm{YNH}$ subjects, with age and session as factors, showed that $d^{\prime}$ improved significantly over test sessions $(F(2,60)=21.07, p<0.001)$ without a significant age $\times$ session interaction $(F(2,60)=1.13, \mathrm{NS})$. Thus, the learning-related improvements across sessions were similar in $\mathrm{ONH}$ and $\mathrm{YNH}$ subjects.

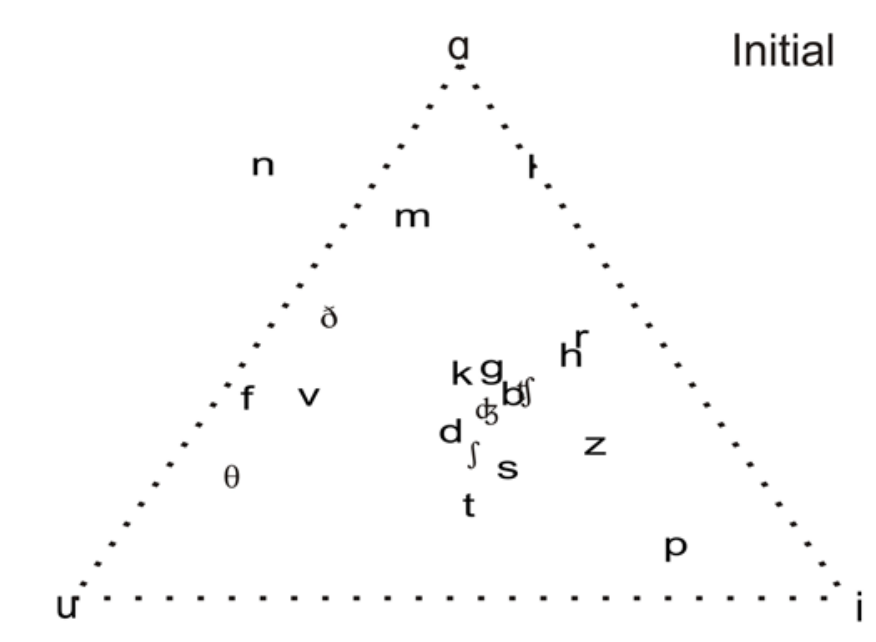

ð

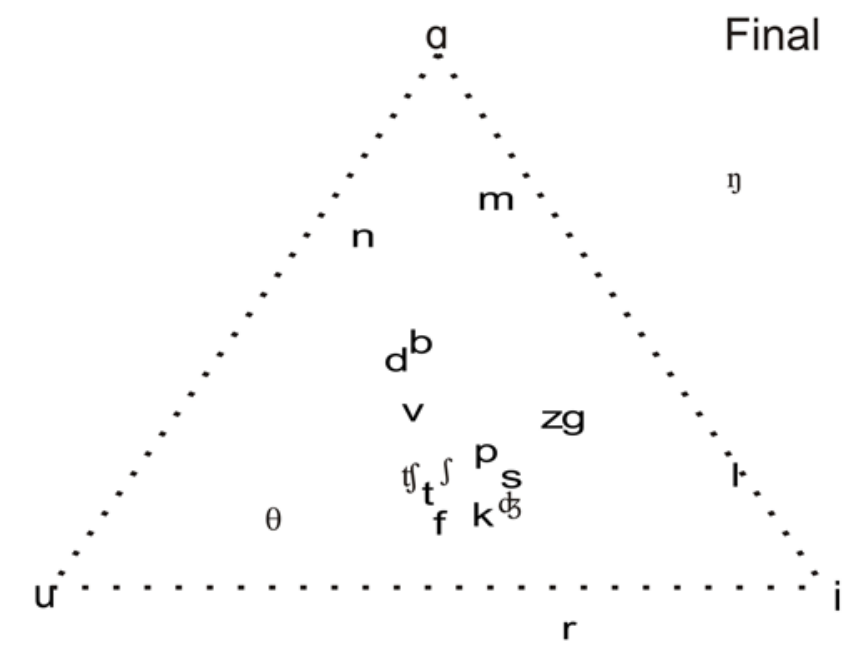

Figure 6.

Vowel influences on consonant processing. Consonant-vowel interactions for older subjects with normal hearing shown on triangular map of vowel space with three vowels presented at apices. Distance of each consonant from each vowel apex is inversely related to $d^{\prime}$ measure for that vowel-consonant combination (top = leading consonants, bottom = coda consonants). Consonants without significant vowel preferences are found near center of triangle. Consonants with strong vowel preferences lie closer to preferred vowel, e.g., nasals are close to $/ \alpha /$.

\section{Lexicality Effects}

Consonant identification is more accurate in words than nonsense syllables for YNH subjects [16]. If $\mathrm{ONH}$ subjects showed reduced lexicality benefits, it would contribute to age-related differences in overall consonant identification thresholds. We therefore performed an ANOVA with age, consonant, position, and lexicality as 


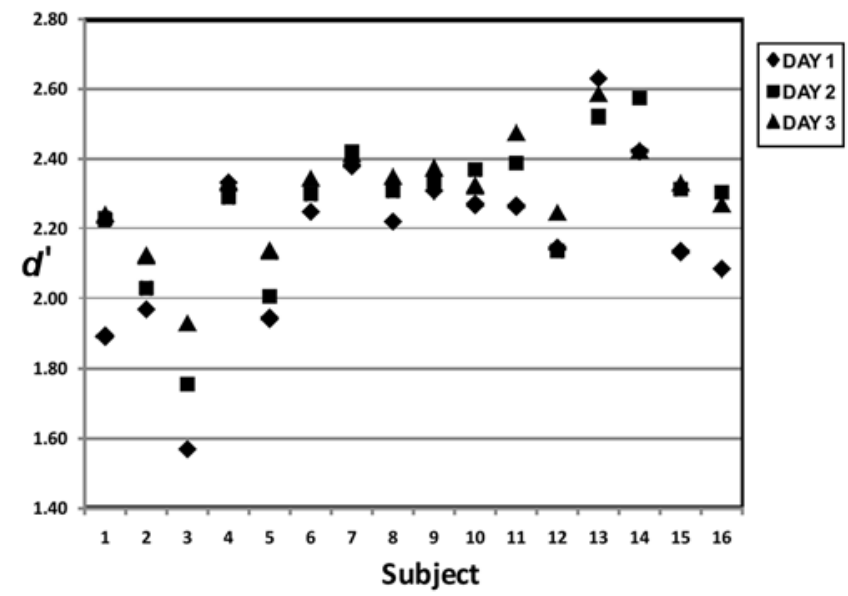

Figure 7.

Learning effects: mean $d^{\prime}$ scores for 16 older subjects over 3 days of testing.

factors. Subjects more accurately reported consonants in words than in nonsense syllables (by $0.18 d^{\prime}$ units, $F(1,30)=118.9, p<0.001)$. In addition, there was a significant lexicality $\times$ consonant interaction $(F(18,540)=$ $6.14, p<0.001)$, indicating that the word-advantage was not uniform for different consonants [16]. There was also a lexicality $\times$ position interaction $(F(1,30)=6.51, p<$ 0.02 ) because the word advantage was larger for leading than for trailing consonants. Importantly, the effects of lexicality were similar in $\mathrm{ONH}$ and $\mathrm{YNH}$ subject groups: the age $\times$ lexicality $(F(1,30)=2.29, \mathrm{NS})$ and age $\times$ lexicality $\times$ position interactions $(F(1,30)=0.18, \mathrm{NS})$ failed to reach significance.

\section{DISCUSSION}

We found that $\mathrm{ONH}$ subjects showed age-related decrements in consonant identification performance that could not be completely explained by audiometric differences with the YNH group. Thus, our results replicate and extend the results of Gelfand et al., who found that aging produced a deterioration in consonant identification [15]. Aging significantly impaired consonant identification independent of age-related changes in audiometric thresholds, as in previous studies [4]. Agerelated reductions in consonant identification have been related to a reduced ability to analyze consonant features [24] without alterations in masking functions [25].
Increased difficulty in word identification has previously been reported in older subjects [9] and persists after factoring out the contribution of age-related differences in audiometric thresholds [19]. Here, we found that consonant identification was similarly affected by age in both words and nonsense syllables. We also found that agerelated changes disproportionately impaired the identification of difficult consonants and, as a result, produced alterations in consonant confusion patterns. Other qualitative aspects of consonant identification, including the effects of vowels and learning, were similar in $\mathrm{ONH}$ and YNH listeners.

Age-related changes in consonant identification ability were found to persist after factoring out audiometric measures and therefore appear to reflect alterations in central auditory processing independently from hearing acuity. Age-related impairments in more basic auditory processes, such as the utilization of binaural cues [26], frequency discrimination [27-28], and the discrimination of fine temporal features of stimuli [28-29], have also been suggested to reflect changes in central auditory processing. Age-related changes are also found in physiological responses [7,30], including slowed transmission of auditory signals in the brainstem [31] and acoustic radiations [32]. Magnetic resonance imaging (MRI) studies reveal age-related reductions in the myelination and the packing density of fiber tracts [33]. Moreover, in functional MRI studies, regions of auditory cortex implicated in phonological processing [34] show age-related reductions in activation magnitude and reduced cortical volume [35].

Age-related elevations of consonant thresholds differed significantly for different consonants and appear to reflect two factors: (1) increased noise in the auditory systems of $\mathrm{ONH}$ listeners that impairs the processing of all consonants and (2) losses in high-frequency hearing that disproportionately impair group $\mathrm{C}$ consonant identification. An age-related increase in internal noise was reflected in an increase in the SNR needed to equate consonant $d^{\prime}$ in $\mathrm{ONH}$ and $\mathrm{YNH}$ listeners. If the increased internal noise were similar for all consonants, the SNR increase required to equate performance in $\mathrm{YNH}$ and $\mathrm{ONH}$ subjects would vary with the rate of change in performance (in $d^{\prime} / \mathrm{dB}$ ) that characterizes each consonant. Thus, an identical loss in $d^{\prime}$ sensitivity would produce a smaller dB SNR change for a consonant with a steep performance/intensity $(\mathrm{P} / \mathrm{I})$ function than for a consonant with a shallow $\mathrm{P} / \mathrm{I}$ function. 
Figure 8 plots the magnitude of age-related threshold increases as a function of the $d^{\prime} / \mathrm{dB}$ for the 19 consonants that occurred in both syllable positions. There was a strong correlation between age-related SNR threshold elevations and $d^{\prime} / \mathrm{dB}$ slopes (Pearson $r=0.80$ ). The regression line fit the data well for 16 of 19 consonants. For these 16 consonants, age-related threshold elevations were well predicted from the consonants' $d / d B$ slopes. This implies that age-related increases in internal noise are relatively constant for most consonants (approximately $0.35 d^{\prime}$ units). In contrast, thresholds elevations for three consonants, $/ \delta /, / \theta /$, and $/ f /$, fell well outside the regression function. These low-intensity fricatives showed additional impairment in $\mathrm{ONH}$ subjects that likely reflects age-related reductions in high-frequency hearing sensitivity.

\section{INTRODUCTION: EXPERIMENT 2}

In addition to causing difficulties in consonant identification, aging may cause neuroanatomical [36] and cognitive changes that further disrupt top-down sentence comprehension [37-38]. For example, sentence comprehension in noise may be impaired as a consequence of age-related decrements in processing speed [39], auditory

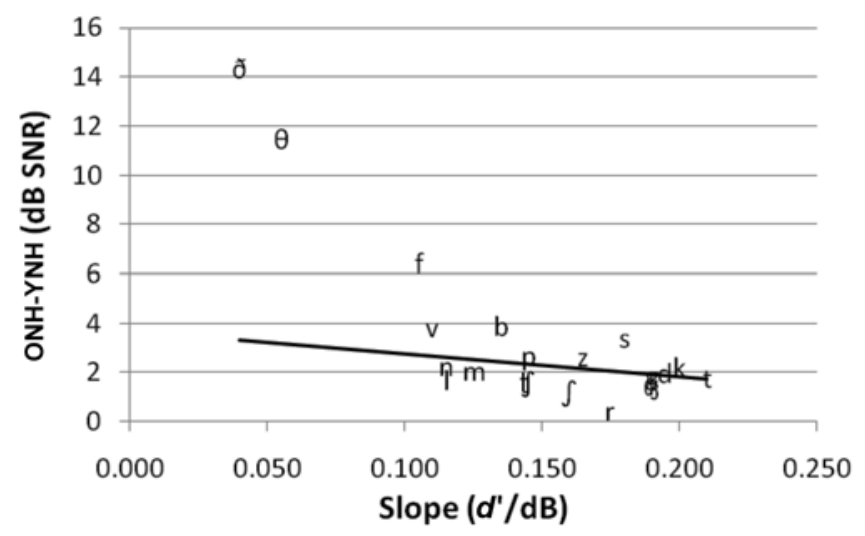

\section{Figure 8.}

Regression functions: regression function showing relationship between performance/intensity slope for different consonants and age-related $\mathrm{dB}$ signal-to-noise (SNR) ratio threshold difference for each of 19 consonants that occurred in both leading and coda syllable positions. Values have been averaged over leading and coda consonants. $\mathrm{ONH}=$ older subjects with normal hearing, $\mathrm{YNH}=$ younger subjects with normal hearing. stream segregation [40], and auditory memory [41-43]. A number of studies have found small age-related increases in SeRTs in ONH subjects [2,37,44-46]. However, other studies have failed to find age-related elevations in SeRTs [19]. For example, Rajan and Cainer found no age-related SeRT elevations when sentences were presented with noise maskers [47] and Tun et al. found intact sentence comprehension in older subjects despite increased response latencies [48]. In experiment 2, we examined age-related changes in SeRTs with the QuickSIN [20] and HINT [21].

\section{METHODS}

\section{Subjects}

All subjects in experiment 1 participated in experiment 2.

\section{Sentence Reception Threshold Testing}

On each day of testing, we measured sentence comprehension using the HINT [21] and the QuickSIN [20]. As in our previous studies [49], HINT and QuickSIN sentences were delivered through the loudspeakers at $70 \mathrm{~dB}$ SPL with varying levels of masking noise.

We measured four independent HINT thresholds on each test day, one threshold for each of four 20 -sentence lists. Each measurement began with the first sentence presented at $6 \mathrm{~dB}$ SNR. The SNR was then reduced by $4 \mathrm{~dB}$ until the first incorrect report, at which point the SNR was increased by $4 \mathrm{~dB}$. Thereafter, SNRs were increased by $2 \mathrm{~dB}$ following each incorrect report and decreased by $2 \mathrm{~dB}$ following each correct report. The average SNR over the last 16 sentences of the list determined the SNR for the list. We averaged SNRs for the four lists to determine the mean daily threshold.

For each QuickSIN list, six sentences were delivered in four-talker babble at progressively lower SNRs. Each sentence has five key words and the SNR for the list is determined from the total number of key words understood correctly. We computed mean daily QuickSIN thresholds from six independent QuickSIN lists.

We randomized the order of presentation of the three different sets of HINT and QuickSIN sentences across subjects. We used unique HINT and QuickSIN sentence lists on each day of testing so that no sentences were repeated across testing days. 


\section{Statistical Analysis}

We analyzed the data with multivariate ANOVA for repeated measures and correlation analyses as in experiment 1 .

\section{RESULTS}

We found no significant age-related differences in SeRTs for either the QuickSIN (ONH subjects $=0.55 \mathrm{~dB}$, YNH subjects $=0.35 \mathrm{~dB}, F(1,30)=0.25, \mathrm{NS})$ or the HINT $(\mathrm{ONH}$ subjects $=-1.79 \mathrm{~dB}$, YNH subjects $=-1.79 \mathrm{~dB}$, $F(1,30)=0.00$, NS). Further analysis showed that SeRTs were only weakly correlated with audiometric thresholds: HINT thresholds did not correlate with either LPTA $(r=$ $0.17)$ or HPTA $(r=0.07)$, while QuickSIN thresholds correlated weakly with the LPTA $(r=0.31, p<0.05)$ but not significantly with the HPTA $(r=0.22, p<0.3)$. Partial correlation analysis revealed that after factoring out the effects of LTPA and HPTA, SeRTs were not significantly correlated with age for either the QuickSIN $(r=-0.06)$ or the HINT $(r=-0.10)$.

In contrast, significant correlations were found between both QuickSIN and HINT SeRTs and CaST $d^{\prime}$ scores: subjects with better consonant identification performance had lower SeRTs. This was reflected in negative correlations between QuickSIN SeRTs and CaST $d^{\prime}$ scores for group A $(r=-0.56, p<0.001)$, group B $(r=-0.59, p<$ $0.001)$, and group $\mathrm{C}(r=-0.56, p<0.001)$ consonants and between HINT SeRTs and group A $(r=-0.49, p<0.005)$, group B $(r=-0.42, p<0.01)$, and group $\mathrm{C}(r=-0.38, p<$ $0.02)$ consonant $d^{\prime}$. Correlations between CaST $d^{\prime}$ scores and SeRTs were also significant within the $\mathrm{YNH}$ and $\mathrm{ONH}$ subject groups when analyzed individually.

We performed further analyses of the effects of age on SeRTs after factoring out the contributions of LPTA, HPTA, and group A and group B consonant identification performance. We excluded group $\mathrm{C}$ consonants because they cannot be identified at the SNRs used in SeRT testing. Significant age-effects were evident: increasing age was associated with better SeRTs on the QuickSIN $(r=-0.50$, $p<0.003)$ and HINT $(r=-0.36, p<0.02)$ than was predicted based on combined audiometric and CaST results.

\section{DISCUSSION}

Despite the presence of small but significant agerelated elevations in LPTA, HPTA, and CaST thresholds, experiment 2 failed to find significant age-related changes in SeRTs measured with either the QuickSIN or HINT. This result was particularly surprising because SeRTs showed strong correlations with consonant identification performance. Thus, ONH subjects with impaired consonant identification would be expected to show elevated SeRTs.

However, SeRTs are generally less sensitive to mild hearing loss than measures of consonant identification. In a previous study [16], we found that a patient with mild sensorineural hearing loss (SNHL) showed mean CaST threshold elevations of $8.1 \mathrm{~dB}$, while SeRTs were elevated by only $1.2 \mathrm{~dB}$ on the HINT and $1.8 \mathrm{~dB}$ in the QuickSIN. In the current experiment, the ONH subject group showed smaller consonant threshold elevations, $3.1 \mathrm{~dB}$ overall and only $1.4 \mathrm{~dB}$ for group A consonants. Because group A consonants contribute disproportionately to sentence comprehension at SNRs that characterize SeRTs, preserved group A consonant processing would assist sentence recognition in the ONH subject group.

Indeed, our results showed that the SeRTs of ONH subjects were better than those of YNH subjects after consonant identification performance and audiometric thresholds had been factored out. This result suggests that ONH subjects are better able than YNH subjects to compensate for reduced hearing acuity and reductions in consonant identification ability by relying more on information provided by vowels, intonation, word stress, and semantic cues. Vowel identification is well preserved in mild hearing loss [50] and largely unaffected by age [51]. In addition, ONH subjects are also as good as $\mathrm{YNH}$ subjects at extracting prosodic cues [52] and may be better at processing contextual cues than YNH subjects [1]. Our results suggest that $\mathrm{ONH}$ subjects are better than YNH subjects at extracting context from the sentences materials used in the QuickSIN and HINT. This may reflect a generalized age-related improvement in contextual processing [53-54]. It is also possible that the sentences used in the QuickSIN and HINT, which were created in 1969 (QuickSIN) and the mid-1970s (HINT), provide better contextual cues for $\mathrm{ONH}$ subjects than YNH subjects. 


\section{GENERAL DISCUSSION}

Our results suggest that impairments in speech comprehension in ONH subjects are most clearly found in consonant identification tasks, which reveal both agerelated changes related to increases in audiometric thresholds and age-related central impairments in phonological processing. We found strong correlations between the LPTAs and consonant-identification thresholds, with the largest correlations found with the HPTA and group C consonants. The correlation with the HPTA reflects the fact that group $\mathrm{C}$ consonants are primarily fricatives whose identification depends on information in the highfrequency spectrum. Nevertheless, significant age-related decrements in consonant identification are also seen in group B and group C consonants, even after factoring out audiometric contributions. This suggests that age-related consonant identification deficits reflect decrements in neuronal processing, consistent with age-related changes in physiological measures of auditory brainstem [55] and cortical responses [35].

However, ONH subjects showed no age-related impairments in sentence comprehension in noise measured with either the QuickSIN or the HINT. This likely reflects the minimal age-related elevation in group A consonant thresholds and the fact that $\mathrm{ONH}$ subjects more effectively utilized nonconsonant phonological information as well as syntactic and semantic cues.

\section{CONCLUSIONS}

The results from ONH subjects also establish a point of reference for audiological rehabilitation studies of $\mathrm{OHI}$ subjects with SNHL. The goal of audiological rehabilitation of older subjects would be to achieve performance levels seen in $\mathrm{ONH}$, not $\mathrm{YNH}$, subjects. Fortunately, meaningful elevations in consonant identification thresholds are primarily restricted to a subset of group $\mathrm{C}$ consonants. Most ONH subjects have consonant identification thresholds for group A and group B consonants that fall within the range seen in the YNH population. Importantly, these results suggest that if audiological rehabilitation restored consonant identification in OHI subjects to the level of ONH subjects, OHI subjects would understand sentences in noise as well as $\mathrm{YNH}$ subjects.

\section{ACKNOWLEDGMENTS}

\section{Author Contributions:}

Study concept and design: D. L. Woods, E. W. Yund.

Acquisition of data: Z. Doss, E. W. Yund.

Analysis and interpretation of data: D. L. Woods, T. J. Herron,

E. W. Yund.

Drafting of manuscript: D. L. Woods, Z. Doss.

Critical revision of manuscript for important intellectual content:

D. L. Woods, T. J. Herron, E. W. Yund.

Statistical analysis: D. L. Woods, T. J. Herron, E. W. Yund.

Obtained funding: D. L. Woods.

Administrative, technical, or material support: D. L. Woods,

E. W. Yund.

Study supervision: D. L. Woods.

Financial Disclosures: The authors have declared that no competing interests exist.

Funding/Support: This material was based on work supported by the Department of Veterans Affairs Rehabilitation Research and Development Service (grant C4739R).

Institutional Review: All subjects gave informed consent following procedures approved by the Department of Veterans Affairs Northern California Health Care System Institutional Review Board and were paid for their participation.

Participant Follow-Up: The authors do not plan to inform participants of the publication of this study.

\section{REFERENCES}

1. CHABA. Speech understanding and aging. Working Group on Speech Understanding and Aging. Committee on Hearing, Bioacoustics, and Biomechanics, Commission on Behavioral and Social Sciences and Education, National Research Council. J Acoust Soc Am. 1988;83(3):859-95. [PMID:3281988]

2. Divenyi PL, Haupt KM. Audiological correlates of speech understanding deficits in elderly listeners with mild-tomoderate hearing loss. II. Correlation analysis. Ear Hear. 1997;18(2):100-113. [PMID:9099559] http://dx.doi.org/10.1097/00003446-199704000-00002

3. Divenyi PL, Stark PB, Haupt KM. Decline of speech understanding and auditory thresholds in the elderly. J Acoust Soc Am. 2005;118(2):1089-1100. [PMID:16158663] http://dx.doi.org/10.1121/1.1953207

4. Helfer KS, Wilber LA. Hearing loss, aging, and speech perception in reverberation and noise. J Speech Hear Res. 1990;33(1):149-55. [PMID:2314073]

5. Abel SM, Sass-Kortsak A, Naugler JJ. The role of highfrequency hearing in age-related speech understanding deficits. Scand Audiol. 2000;29(3):131-38. [PMID:10990011] http://dx.doi.org/10.1080/010503900750042699 
6. Aydelott J, Leech R, Crinion J. Normal adult aging and the contextual influences affecting speech and meaningful sound perception. Trends Amplif. 2010;14(4):218-32.

[PMID:21307006]

http://dx.doi.org/10.1177/1084713810393751

7. Gates GA, Feeney MP, Mills D. Cross-sectional agechanges of hearing in the elderly. Ear Hear. 2008;29(6): 865-74. [PMID:18998241] http://dx.doi.org/10.1097/AUD.0b013e318181adb5

8. Gelfand SA, Piper N, Silman S. Consonant recognition in quiet as a function of aging among normal hearing subjects. J Acoust Soc Am. 1985;78(4):1198-1206.

[PMID:4056214] http://dx.doi.org/10.1121/1.392888

9. Wilson RH, McArdle R. Speech signals used to evaluate functional status of the auditory system. J Rehabil Res Dev. 2005;42(4 Suppl 2):79-94. [PMID:16470466] http://dx.doi.org/10.1682/JRRD.2005.06.0096

10. Mendel LL. Objective and subjective hearing aid assessment outcomes. Am J Audiol. 2007;16(2):118-29.

[PMID:18056880] http://dx.doi.org/10.1044/1059-0889(2007/016)

11. Woods DL, Yund EW. Perceptual training of phoneme identification for hearing loss. Semin Hear. 2007;28:110-19. http://dx.doi.org/10.1055/s-2007-973437

12. Gordon-Salant S. Recognition of natural and time/intensity altered CVs by young and elderly subjects with normal hearing. J Acoust Soc Am. 1986;80(6):1599-1607. [PMID:3794065] http://dx.doi.org/10.1121/1.394324

13. Gordon-Salant S. Effects of acoustic modification on consonant recognition by elderly hearing-impaired subjects. J Acoust Soc Am. 1987;81(4):1199-1202. [PMID:3571732] http://dx.doi.org/10.1121/1.394643

14. Helfer KS, Huntley RA. Aging and consonant errors in reverberation and noise. J Acoust Soc Am. 1991;90(4 Pt 1): 1786-96. [PMID:1960274] http://dx.doi.org/10.1121/1.401659

15. Gelfand SA, Piper N, Silman S. Consonant recognition in quiet and in noise with aging among normal hearing listeners. J Acoust Soc Am. 1986;80(6):1589-98.

[PMID:3794064]

http://dx.doi.org/10.1121/1.394323

16. Woods DL, Yund EW, Herron TJ. Measuring consonant identification in nonsense syllables, words, and sentences. J Rehabil Res Dev. 2010;47(3):243-60. [PMID:20665350] http://dx.doi.org/10.1682/JRRD.2009.04.0040

17. Woods DL, Yund EW, Herron TJ, Ua Cruadhlaoich MA. Consonant identification in consonant-vowel-consonant syllables in speech-spectrum noise. J Acoust Soc Am. 2010;
127(3):1609-23. [PMID:20329860]

http://dx.doi.org/10.1121/1.3293005

18. Gordon-Salant S. Consonant recognition and confusion patterns among elderly hearing-impaired subjects. Ear Hear. 1987;8(5):270-76. [PMID:3678640]

http://dx.doi.org/10.1097/00003446-198710000-00003

19. Dubno JR, Lee FS, Matthews LJ, Mills JH. Age-related and gender-related changes in monaural speech recognition. J Speech Lang Hear Res. 1997;40(2):444-52.

[PMID:9130212]

20. Killion MC, Niquette PA, Gudmundsen GI, Revit LJ, Banerjee S. Development of a quick speech-in-noise test for measuring signal-to-noise ratio loss in normal-hearing and hearing-impaired listeners. J Acoust Soc Am. 2004;116(4 Pt 1):2395-2405. [PMID:15532670] http://dx.doi.org/10.1121/1.1784440

21. Nilsson M, Soli SD, Sullivan JA. Development of the Hearing in Noise Test for the measurement of speech reception thresholds in quiet and in noise. J Acoust Soc Am. 1994;95(2):1085-99. [PMID:8132902]

http://dx.doi.org/10.1121/1.408469

22. Greenhouse SW, Geisser S. On methods in the analysis of profile data. Psychometrika. 1959;24(2):95-112. http://dx.doi.org/10.1007/BF02289823

23. Whittaker J. Graphical models in applied multivariate statistics. Chichester (England): Wiley; 1990.

24. Gordon-Salant S, Yeni-Komshian GH, Fitzgibbons PJ, Barrett J. Age-related differences in identification and discrimination of temporal cues in speech segments. J Acoust Soc Am. 2006;119(4):2455-66. [PMID:16642858] http://dx.doi.org/10.1121/1.2171527

25. Cheesman MF, Hepburn D, Armitage JC, Marshall K. Comparison of growth of masking functions and speech discrimination abilities in younger and older adults. Audiology. 1995;34(6):321-33. [PMID:8833312] http://dx.doi.org/10.3109/00206099509071922

26. Pichora-Fuller MK, Schneider BA. Masking-level differences in older adults: the effect of the level of the masking noise. Percept Psychophys. 1998;60(7):1197-1205.

[PMID:9821781] http://dx.doi.org/10.3758/BF03206169

27. Cranford JL, Stream RW. Discrimination of short duration tones by elderly subjects. J Gerontol. 1991;46(1):37-41. [PMID:1986043]

28. Divenyi PL, Haupt KM. Audiological correlates of speech understanding deficits in elderly listeners with mild-tomoderate hearing loss. III. Factor representation. Ear Hear. 1997;18(3):189-201. [PMID:9201454] http://dx.doi.org/10.1097/00003446-199706000-00002

29. Strouse A, Ashmead DH, Ohde RN, Grantham DW. Temporal processing in the aging auditory system. J Acoust Soc 
JRRD, Volume 49, Number 8, 2012

Am. 1998;104(4):2385-99. [PMID:10491702]

http://dx.doi.org/10.1121/1.423748

30. Martin JS, Jerger JF. Some effects of aging on central auditory processing. J Rehabil Res Dev. 2005;42(4 Suppl 2): 25-44. [PMID:16470463] http://dx.doi.org/10.1682/JRRD.2004.12.0164

31. Rosenhall U, Pedersen K, Dotevall M. Effects of presbycusis and other types of hearing loss on auditory brainstem responses. Scand Audiol. 1986;15(4):179-85. [PMID:3563395] http://dx.doi.org/10.3109/01050398609042141

32. Woods DL, Clayworth CC. Age-related changes in human middle latency auditory evoked potentials. Electroencephalogr Clin Neurophysiol. 1986;65(4):297-303. [PMID:2424742] http://dx.doi.org/10.1016/0168-5597(86)90008-0

33. Zahr NM, Rohlfing T, Pfefferbaum A, Sullivan EV. Problem solving, working memory, and motor correlates of association and commissural fiber bundles in normal aging: a quantitative fiber tracking study. Neuroimage. 2009; 44(3):1050-62. [PMID:18977450]

http://dx.doi.org/10.1016/j.neuroimage.2008.09.046

34. Woods DL, Herron TJ, Cate AD, Kang X, Yund EW. Phonological processing in human auditory cortical fields. Front Hum Neurosci. 2011;5:42. [PMID:21541252] http://dx.doi.org/10.3389/fnhum.2011.00042

35. Harris KC, Dubno JR, Keren NI, Ahlstrom JB, Eckert MA. Speech recognition in younger and older adults: a dependency on low-level auditory cortex. J Neurosci. 2009; 29(19):6078-87. [PMID:19439585] http://dx.doi.org/10.1523/JNEUROSCI.0412-09.2009

36. Wong PC, Ettlinger M, Sheppard JP, Gunasekera GM, Dhar S. Neuroanatomical characteristics and speech perception in noise in older adults. Ear Hear. 2010;31(4):471-79. [PMID:20588117] http://dx.doi.org/10.1097/AUD.0b013e3181d709c2

37. George EL, Zekveld AA, Kramer SE, Goverts ST, Festen JM, Houtgast T. Auditory and nonauditory factors affecting speech reception in noise by older listeners. J Acoust Soc Am. 2007;121(4):2362-75. [PMID:17471748]

http://dx.doi.org/10.1121/1.2642072

38. Stewart R, Wingfield A. Hearing loss and cognitive effort in older adults' report accuracy for verbal materials. J Am Acad Audiol. 2009;20(2):147-54. [PMID:19927677] http://dx.doi.org/10.3766/jaaa.20.2.7

39. Van Rooij JC, Plomp R. Auditive and cognitive factors in speech perception by elderly listeners. Acta Otolaryngol Suppl. 1990;476:177-81. [PMID:2087960]

40. Alain C, Ogawa KH, Woods DL. Aging and the segregation of auditory stimulus sequences. J Gerontol B Psychol Sci Soc Sci. 1996;51B(2):P91-93. http://dx.doi.org/10.1093/geronb/51B.2.P91
41. Gordon-Salant S, Fitzgibbons PJ. Selected cognitive factors and speech recognition performance among young and elderly listeners. J Speech Lang Hear Res. 1997;40(2):423-31. [PMID:9130210]

42. Rönnberg J, Danielsson H, Rudner M, Arlinger S, Sternäng $\mathrm{O}$, Wahlin A, Nilsson LG. Hearing loss is negatively related to episodic and semantic long-term memory but not to short-term memory. J Speech Lang Hear Res. 2011;54(2): 705-26. [PMID:20884779] http://dx.doi.org/10.1044/1092-4388(2010/09-0088)

43. Surprenant AM. Effects of noise on identification and serial recall of nonsense syllables in older and younger adults. Neuropsychol Dev Cogn B Aging Neuropsychol Cogn. 2007;14(2):126-43. [PMID:17364376] http://dx.doi.org/10.1080/13825580701217710

44. Divenyi PL, Haupt KM. Audiological correlates of speech understanding deficits in elderly listeners with mild-tomoderate hearing loss. I. Age and lateral asymmetry effects. Ear Hear. 1997;18(1):42-61. [PMID:9058037] http://dx.doi.org/10.1097/00003446-199702000-00005

45. Gelfand SA, Ross L, Miller S. Sentence reception in noise from one versus two sources: effects of aging and hearing loss. J Acoust Soc Am. 1988;83(1):248-56.

[PMID:3343444] http://dx.doi.org/10.1121/1.396426

46. Versfeld NJ, Dreschler WA. The relationship between the intelligibility of time-compressed speech and speech in noise in young and elderly listeners. J Acoust Soc Am. 2002; 111(1 Pt 1):401-8. [PMID:11831813] http://dx.doi.org/10.1121/1.1426376

47. Rajan R, Cainer KE. Ageing without hearing loss or cognitive impairment causes a decrease in speech intelligibility only in informational maskers. Neuroscience. 2008;154(2): 784-95. [PMID:18485606] http://dx.doi.org/10.1016/j.neuroscience.2008.03.067

48. Tun PA, Benichov J, Wingfield A. Response latencies in auditory sentence comprehension: effects of linguistic versus perceptual challenge. Psychol Aging. 2010;25(3):730-35. [PMID:20853977] http://dx.doi.org/10.1037/a0019300

49. Yund EW, Woods DL. Content and procedural learning in repeated sentence tests of speech perception. Ear Hear. 2010;31(6):769-78. [PMID:20562624] http://dx.doi.org/10.1097/AUD.0b013e3181e68e4a

50. Kuk F, Lau CC, Korhonen P, Crose B, Peeters H, Keenan D. Development of the ORCA nonsense syllable test. Ear Hear. 2010;31(6):779-95. [PMID:20622673] http://dx.doi.org/10.1097/AUD.0b013e3181e97bfb

51. Ohde RN, Abou-Khalil R. Age differences for stop-consonant and vowel perception in adults. J Acoust Soc Am. 2001;110(4):2156-66. [PMID:11681392] http://dx.doi.org/10.1121/1.1399047 
WOODS et al. Aging and speech comprehension

52. Wingfield A, Lindfield KC, Goodglass H. Effects of age and hearing sensitivity on the use of prosodic information in spoken word recognition. J Speech Lang Hear Res. 2000;43(4): 915-25. [PMID:11386478]

53. Pichora-Fuller MK, Schneider BA, Daneman M. How young and old adults listen to and remember speech in noise. J Acoust Soc Am. 1995;97(1):593-608.

[PMID:7860836]

http://dx.doi.org/10.1121/1.412282

54. Uslar V, Ruigendijk E, Hamann C, Brand T, Kollmeier B. How does linguistic complexity influence intelligibility in a German audiometric sentence intelligibility test? Int J Audiol. 2011;50(9):621-31. [PMID:21714708] http://dx.doi.org/10.3109/14992027.2011.582166

55. Vander Werff KR, Burns KS. Brain stem responses to speech in younger and older adults. Ear Hear. 2011;32(2):
168-80. [PMID:21052004]

http://dx.doi.org/10.1097/AUD.0b013e3181f534b5

Submitted for publication August 24, 2011. Accepted in revised form February 8, 2012.

This article and any supplementary material should be cited as follows:

Woods DL, Doss Z, Herron TJ, Yund EW. Age-related changes in consonant and sentence processing. J Rehabil Res Dev. 2012;49(8):1277-92.

http://dx.doi.org/10.1682/JRRD.2011.08.0150

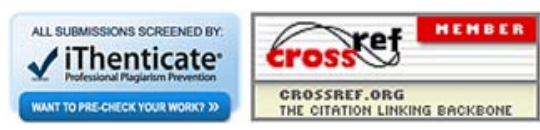

